surgical treatment. Finally, pathologists must be aware that RDD should be considered among the possible differential diagnoses for cardiovascular tumors.

\section{References}

1. Foucar E, Rosai J, Dorfman R. Sinus histiocytosis with massive lymphadenopathy (Rosai-Dorfman disease): review of the entity. Semin Diagn Pathol. 1990;7:19-73.

2. Paulli M, Bergamaschi G, Tonon L, Viglio A, Rosso R, Facchetti F, et al. Evidence of a polyclonal nature of the cell infiltrate in sinus histiocytosis with massive lymphadenopathy (Rosai-Dorfman disease). Br J Haematol. 1995;91: 415-8.

3. Walters DM, Dunnington GH, Dustin SM, Frierson HF, Peeler BB, Kozower BD, et al. Rosai-Dorfman disease presenting as a pulmonary artery mass. Ann Thorac Surg. 2010;89:300-2.

4. Ajise OE, Stahl-Herz J, Goozner B, Cassai N, McRae G, Wieczorek R. Extranodal Rosai-Dorfman disease arising in the right atrium: a case report with literature review. Int J Surg Pathol. 2011;19:637-42.

5. Prendes BL, Brinkman WT, Sengupta AL, Bavaria JE. Atypical presentation of extranodal Rosai-Dorfman disease. Ann Thorac Surg. 2009;87: 616-8.

\title{
Pseudo-dextrocardia: An unusual case of giant biatrial enlargement
}

\author{
Roberto Lorusso, MD, PhD, ${ }^{\mathrm{a}}$ Mario Morone, MD, ${ }^{\mathrm{b}}$ Davide Farina, $\mathrm{MD},{ }^{\mathrm{b}}$ and \\ Sandro Gelsomino, $\mathrm{MD}, \mathrm{PhD},{ }^{\mathrm{a}}$ Brescia, Italy
}

Giant dilatation of cardiac atria is usually confined to 1 chamber, very rarely to both, and is mainly related to rheumatic valve diseases of the left heart. ${ }^{1-3}$ Cases of left atrial enlargement have also been reported with a normally functioning mitral or aortic valve and extremely rarely in the presence of nonrheumatic mitral insufficiency., ${ }^{2,3}$ The combination of giant bilateral atrial dilatation and the need of reoperation for cardiac prosthetic dysfunction can pose additional risks because of adhesions and a thin right atrial wall. Furthermore, the unusual cardiac displacement induced by excessive atrial enlargement can jeopardize, or even impede, conventional access to the major vessels for extracorporeal circulation (ECC).

We report the case of a patient who had presented with a "pseudo-dextrocardia" found by chest radiography. The pseudo-dextrocardia was induced by an unusual bilateral atrial dilatation. The patient required a third operation for a paravalvular leak of a mitral prosthesis.

\section{CLINICAL REPORT}

A 62-year-old man was referred to our hospital for increasing dyspnea. At 25 years old, he had undergone mitral commissurotomy; 12 years later, he had undergone mitral-aortic replacement and tricuspid valve repair for rheumatic-related valve disease. Marked bilateral

\footnotetext{
From the Cardiac Surgery Unit ${ }^{\mathrm{a}}$ and Radiology Unit, ${ }^{\mathrm{b}}$ Community Hospital, Brescia, Italy.

Disclosures: Authors have nothing to disclose with regard to commercial support.

Received for publication June 6, 2013; revisions received July 20, 2013; accepted for publication Aug 1, 2013; available ahead of print Sept 23, 2013.

Address for reprints: Roberto Lorusso, MD, PhD, Cardiac Surgery Unit, Community Hospital, Piazzale Spedali Civili, 1, Brescia 25128, Italy (E-mail: ro.lorusso@ libero.it).

J Thorac Cardiovasc Surg 2013;146:e59-61

$0022-5223 / \$ 36.00$

Copyright (C) 2013 by The American Association for Thoracic Surgery

http://dx.doi.org/10.1016/j.jtcvs.2013.08.014
}

atriomegaly had been present since the first surgical procedure because of severe mitral stenosis with moderate tricuspid regurgitation, which had not been addressed during that operation. Additional progression of the atrial dilatation had developed owing to the recurrence of severe mitral stenosis, the development of severe aortic stenosis, and the development of tricuspid insufficiency requiring reoperation. At that point, because of the tight adhesions between the right ventricle and right atrium and the sternum, making sternal reentry troublesome, a right anterior minithoracotomy had been performed to enhance adhesion dissection and allow safer median sternotomy. Severe bleeding had nonetheless occurred, although it was finally controlled, allowing a triplevalve operation. The patient subsequently did well until a few months before his latest hospitalization for shortness of breath. At hospital admission, the chest radiograph showed a huge cardiac enlargement, mimicking a dextrocardia, and diffuse adhesions between the right cardiac structures and the sternum (Figure 1). The anatomic features were confirmed by computed tomography (Figure 2). Severe hemolysis was also detected from the blood test results, with marked anemia and initial signs of liver dysfunction. Transesophageal echocardiography showed severe mitral regurgitation due to a large posteromedial paravalvular leak, normal function of the aortic mechanical prosthesis and tricuspid valve, and a very short ascending aorta, making direct access for cannulation or the application of an endovascular aortic clamping unfeasible or extremely dangerous. A right thoracotomy approach and femoral-femoral ECC was therefore scheduled. The patient was cooled down to $24^{\circ} \mathrm{C}$ to induce ventricular fibrillation and allow a short period of circulatory arrest, avoiding aortic clamping. The left atrium was approached with extreme difficulty after dissection of dense adhesions 

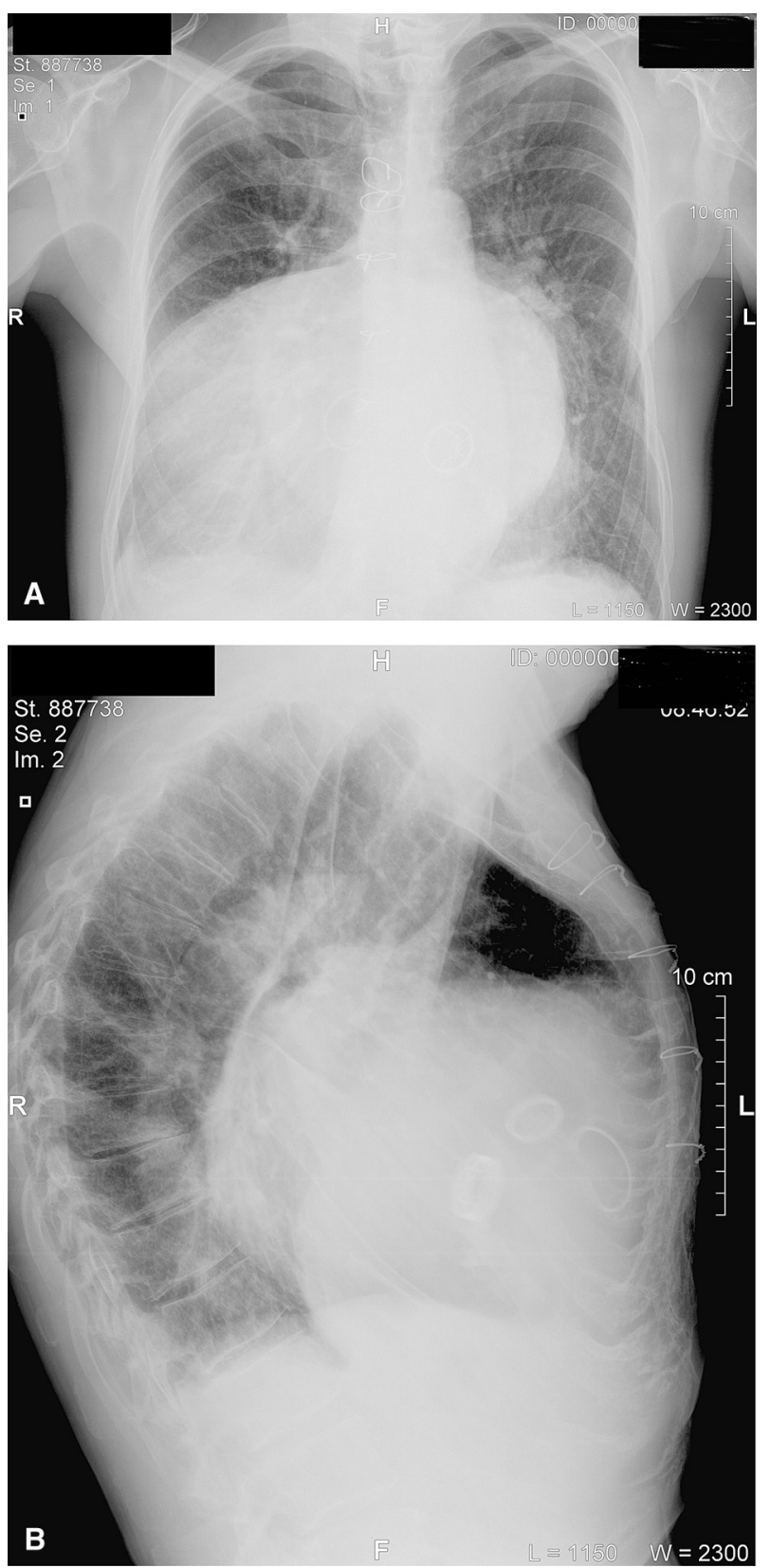

FIGURE 1. A, Anteroposterior chest radiograph showing the "pseudodextrocardia" induced by severe enlargement of the right and left atria, with a right and posterior shifting of the cardiac chambers. B, Laterallateral chest radiograph showing the position of the 2 prosthetic valves at the mitral-aortic level and the tricuspid ring, with evidence of dense adhesions between the right ventricle and atrium toward the inferior surface of the sternum. $L$, Left; $R$, right.

and opened. The mitral paravalvular leak was repaired with a few interrupted pledget-reinforced stitches. A transprosthetic left ventricular vent was inserted during atrial closure to enhance ventricular de-airing while performing left atrial closure after cardiac defibrillation through external pads. After ECC discontinuation, transesophageal echocardiography documented the absence of residual

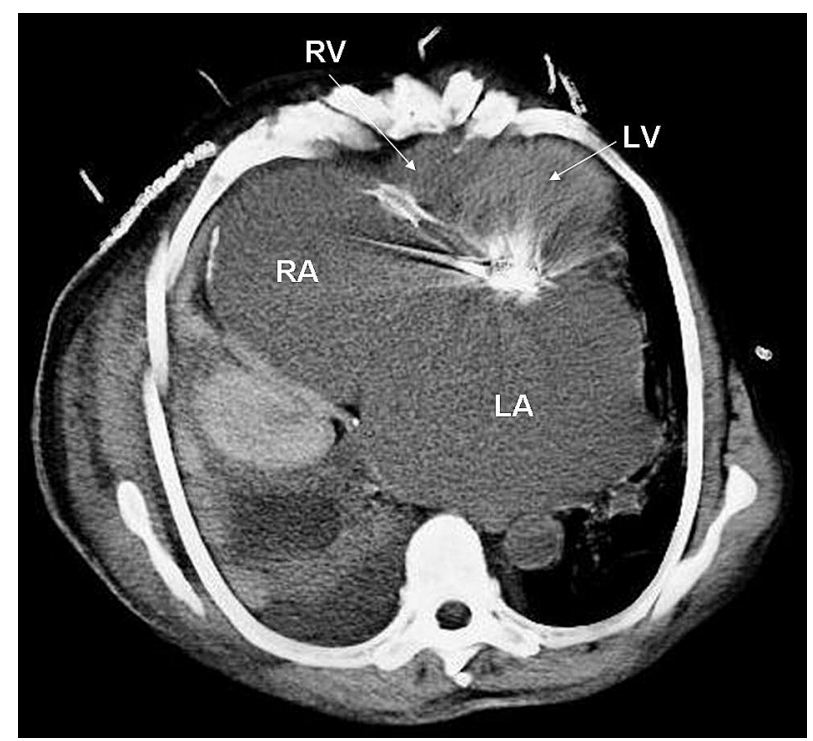

FIGURE 2. Axial thoracic computed tomography scan showing massive dilatation of both right $(R A)$ and left atria $(L A)$ with normal-size right $(R V)$ and left ventricles $(L V)$. The inferior lobe of the right lung had collapsed. Pleural effusion was also present.

paravalvular leaks. The patient was extubated after 28 hours and eventually discharged on postoperative day 9 . At 12 months postoperatively, the patient was in good condition, with no recurrence of paravalvular leakage found by transesophageal echocardiography.

\section{CONCLUSIONS}

Marked enlargement of the left atrium due to mitral valve disease is rarely encountered, and giant atria are even more uncommon in modern cardiovascular medicine because of the decreased prevalence of rheumatic disease. In the case of 1 bilateral atrial enlargement, the chest radiograph might show a sort of "pseudo-dextrocardia" owing to the enormous dilatation confined to both atria without ventricular involvement and clockwise heart rotation. Extreme atrial enlargement can be surgically challenging, particularly if associated with a thin right atrial wall or in the case of reoperation. ${ }^{1}$ A giant left atrium has been surgically addressed using several techniques, ranging from partial plication to radical autotransplanta$\operatorname{tion}^{3,4}$ to prevent the complications usually related to severely enlarged atrial chamber or to restore sinus rhythm in patients with atrial fibrillation. ${ }^{1}$ Giant biatrial enlargement, however, has not been surgically addressed for remodeling and could represent a challenge, particularly in redo operations. Avoiding sternal reentry, minimizing cardiovascular structure dissection, and using peripheral ECC with ventricular fibrillation could all represent advisable surgical strategies to prevent lifethreatening adverse events and allowing the treatment of native or prosthetic valve dysfunction. 


\section{References}

1. Apostolakis E, Shuhaiber JH. The surgical management of giant left atrium. Eur J Cardiothorac Surg. 2008;33:182-90.

2. Rajakaruna C, Mhandu P, Ghosh-Dastidar M, Desai J. Giant left atrium secondary to severe mixed mitral valve pathology. Eur $J$ Cardiothorac Surg. 2007;32:932.
3. Kawazoe K, Beppu S, Takahara Y, Nakajima N, Tanaka K, Ichihashi K, et al. Surgical treatment of giant left atrium combined with mitral valve disease. J Thorac Cardiovasc Surg. 1983;85:885-92.

4. Boldyrev SY, Antipov GN, Porhanov VA. First experience of cardiac autotransplantation for giant left atrium treatment. Interact Cardiovasc Thorac Surg. 2009;8:173-5.

\title{
Effective mechanical cardiac support in a child in the absence of a mitral valve
}

\author{
Matteo Trezzi, MD, ${ }^{a}$ Scott M. Bradley, MD, ${ }^{a}$ Andrew J. Savage, MD, ${ }^{b}$ and Minoo N. Kavarana, MD, ${ }^{a}$ \\ Charleston, SC
}

Although mechanical support for adult heart failure is well established, the options have been limited for children. In particular, little is known about the treatment of children with mechanical mitral valve prostheses undergoing ventricular assist device (VAD) implantation. The current recommendations for adult patients are to leave in place a well-functioning prosthesis while maintaining a higher international normalized ratio postoperatively. ${ }^{1}$ If significant stenosis is present, the recommendation is to perform bioprosthetic valve replacement. ${ }^{2}$ For patients undergoing VAD implantation for complex congenital heart disease, this could significantly increase the duration and morbidity of the procedure.

\section{CASE REPORT}

An 11-year-old girl presented with severe biventricular dysfunction, worsening dyspnea at rest, and a cough with hemoptysis. She had previously undergone neonatal coarctation repair, pulmonary artery banding, and subsequent repair of a complete atrioventricular septal defect and pulmonary artery debanding performed at an outside facility. Over time, she developed severe mitral valve regurgitation, which led to valve repair and, subsequently, replacement with a 21-mm mechanical prosthesis. The latter was complicated by heart block requiring a permanent epicardial pacemaker. Gradually,

\footnotetext{
From the Pediatric Cardiothoracic Surgery Section, ${ }^{a}$ Division of Cardiothoracic Surgery, and Division of Pediatric Cardiology, ${ }^{\mathrm{b}}$ Medical University of South Carolina, Charleston, SC.

Disclosures: Authors have nothing to disclose with regard to commercial support. Received for publication July 10, 2013; revisions received July 28, 2013; accepted for publication Aug 1, 2013; available ahead of print Sept 25, 2013.

Address for reprints: Minoo N. Kavarana, MD, Pediatric Cardiothoracic Surgery Section, Division of Cardiothoracic Surgery, Medical University of South Carolina, 96 Jonathan Lucas St, CSB 424/MSC 613, Charleston, SC 29425-6130 (E-mail: kavarana@musc.edu).

J Thorac Cardiovasc Surg 2013;146:e61-2

$0022-5223 / \$ 36.00$

Copyright (C) 2013 by The American Association for Thoracic Surgery

http://dx.doi.org/10.1016/j.jtcvs.2013.08.002
}

she developed worsening prosthetic mitral stenosis. Her echocardiogram showed a mean mitral gradient of 14 $\mathrm{mm} \mathrm{Hg}$, dilated left and right ventricles with severely depressed function, moderate aortic insufficiency, and severe tricuspid valve regurgitation. During a brief period of evaluation, her hemodynamics deteriorated, with evidence of progressive end-organ dysfunction despite maximal medical therapy. The decision was made to urgently institute mechanical support as a bridge to transplantation.

Cardiopulmonary bypass was established through groin cannulation, and a reoperative median sternotomy was performed. The adhesions were significant, and the left ventricle (LV) was severely dilated, occupying the entire left hemithorax. After cardioplegic arrest, left atriotomy was performed. The mechanical mitral valve prosthesis had extensive pannus overgrowth, with a very small effective orifice area. We decided that excision of this stenotic prosthetic valve would provide the simplest solution. With knowledge of a previous report of this unsuccessful strategy using LV apical cannulation, ${ }^{3}$ we decided to

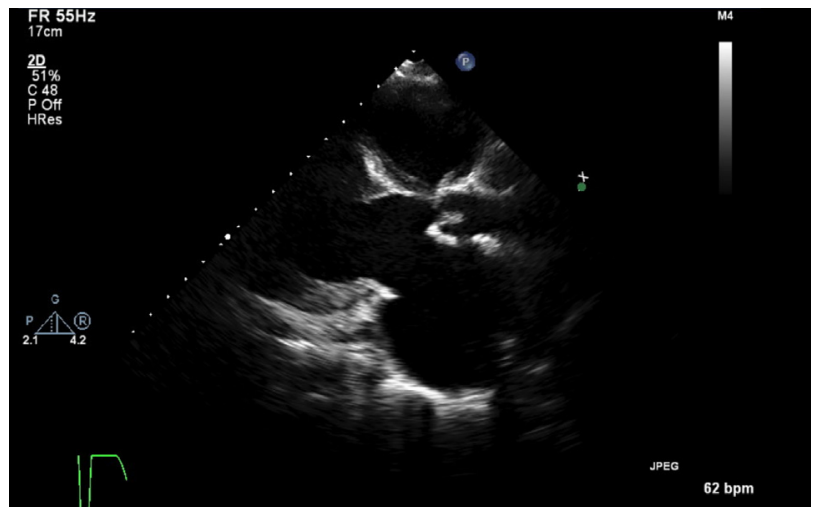

FIGURE 1. Parasternal, 2-dimensional, long-axis view showing absent mitral valve and thickened aortic valve cusps after repair. 